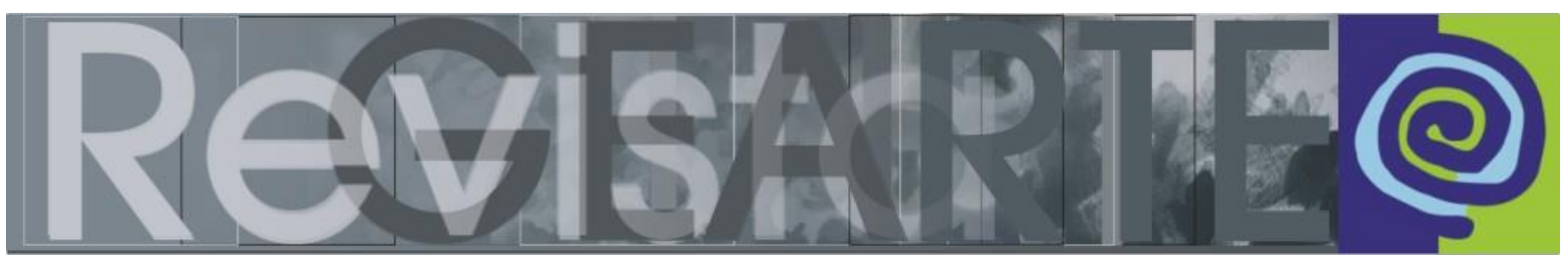

ISSN 2357-9854 | e-ISSN 2596-3198 (online)

\title{
Resenha do livro: Intertextualidades visuais
}

\author{
Moema Martins Rebouças (i) \\ (Universidade Federal do Espírito Santo - UFES, Vitória/ES, Brasil)
}

RESUMO - Resenha do livro: Intertextualidades visuais - A resenha apresenta a publicação Intertextualidades visuais, de Sandra Ramalho e Oliveira e Airton Jordani. Contém uma síntese dos capítulos e propõe refletir sobre a pesquisa realizada pelos autores. Analisa a destinação da publicação para um público-alvo de interessados em estudos voltados aos sentidos dos textos e do percurso da linguagem.

\section{PALAVRAS-CHAVE}

Intertextualidades. Semiótica. Visualidades. Educação em Arte.

ABSTRACT - Book review: Visual intertextualities - The review presents the publication Visual intertextualities by Sandra Ramalho e Oliveira and Airton Jordani. It contains a summary of the chapters and proposes to reflect on the research carried out by the authors. It analyzes the publication's destination to a target audience of people interested in studies about the meanings of texts and the language path.

KEYWORDS

Intertextualities. Semiotics. Visualities. Art Education.

RESUMEN — Reseña del libro: Intertextualidades visuales - La reseña presenta la publicación Intertextualidades visuais, de Sandra Ramalho e Oliveira y Airton Jordani. Contiene un resumen de los capítulos y propone reflexionar sobre la investigación realizada por los autores. Analiza el destino de la publicación para un público objetivo de personas interesadas en estudios centrados en los significados de los textos y el curso del lenguaje.

PALABRAS CLAVE

Intertextualidades. Semiótica. Visualidades. Educación Artística. 


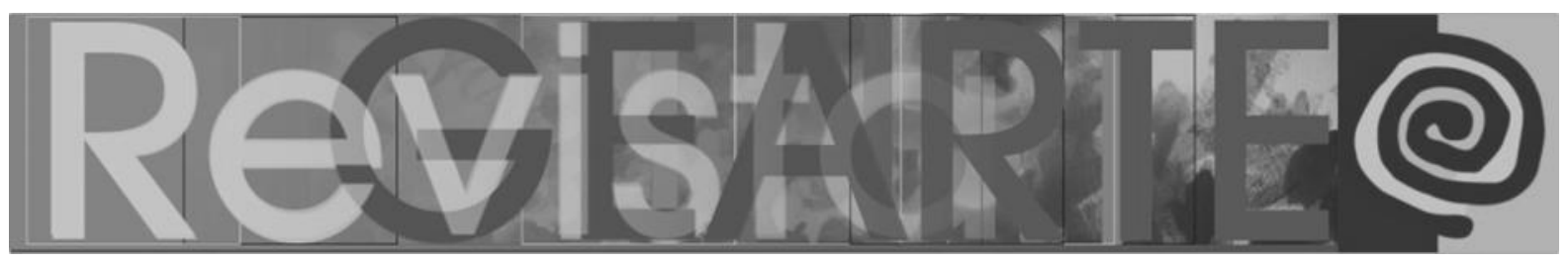

A capa e a contracapa têm em sua superfície de fundo a cor vermelhovioleta e, numa organização espacial, os nomes dos autores estão na parte de cima, em tons rosados e, na parte de baixo, o título da publicação e a logomarca da editora em branco. No meio, com um pequeno deslocamento para a parte superior, as aspas ocupam mais de um terço da superfície retangular, tanto da capa, como da contracapa do livro. Além da dimensão, o que diferencia a fonte desse sinal gráfico das demais é o efeito de tridimensionalidade produzido por hexágonos em tons que variam do violeta e do rosa ao azul. Ao ocupar essa posição e composição plástica, as aspas repetem figurativamente a sua função: destacar, delimitar e realçar citações, títulos e palavras. As da capa antecedem o texto da publicação, e as da contracapa fecham, finalizam. Continuando com esse percurso figurativo, escolhido pelo designer Airton Jordani, ao abrirmos o livro, na folha de rosto, encontramos a mesma informação e organização espacial da capa, entretanto, em preto e branco e com a fonte das aspas maiores. Tal escolha reitera o uso e o sentido do conceito que é título da publicação.

Inicio a resenha pela leitura da visualidade da capa, pois ela cumpre o papel de "traduzir" o conceito central da intertextualidade sobre o qual os estudos de diferentes manifestações culturais encontram-se organizados nesta publicação.

A intertextualidade é uma condição da linguagem em que um texto se apropria de outro e estabelece um diálogo entre eles. Esse diálogo é a base de muitos textos da cultura. Tomando como exemplo a literatura brasileira e a produção cinematográfica, temos Macunaíma, de Mário de Andrade, publicada em 1928, adaptada para o cinema sob a direção de Joaquim Pedro de Andrade, em 1968; ou, anterior a essa obra, As Memórias Póstumas de Brás Cubas, de Machado de Assis, publicada em 1881 e adaptada para o cinema em 2001, sob a direção de André Klotzel. Nas duas produções, a intertextualidade da produção literária com a cinematográfica é direta, mantém o mesmo título e citações literais da obra de origem. Contudo, a intertextualidade ocorre de outros modos: em alguns deles, há uma apropriação do texto-base, mas subvertendo-o, negando-o e estilizando-o. Esse tipo de diálogo intertextual, mesmo que se utilize de artifícios, 


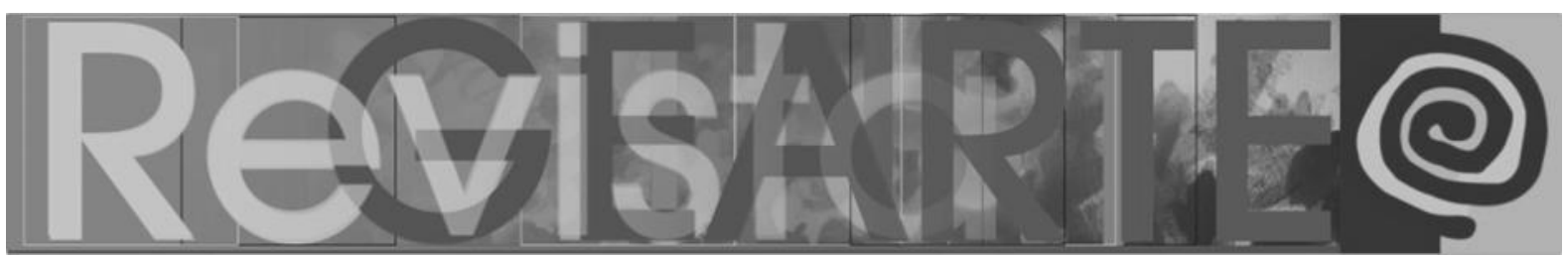

como o de camuflar o texto-base, mantém traços daquele a que faz referência. Enfim, a intertextualidade envolve o diálogo entre os muitos textos da cultura, e este ocorre no ato em que um texto incorpora outro.

Como o discurso não é autônomo, nem fechado, mas aberto e sustentado por muitos textos que se entrecruzam no tempo e no espaço, produzidos por diferentes sujeitos, o desafio dos que interagem com as distintas produções culturais, teatro, cinema, literatura, artes plásticas, dentre outros, é o de examinálos sem perder o foco na produção de sentido que engendram. Esse é o desafio que os autores Sandra Ramalho e Oliveira e Airton Jordani nos oferecem com esta publicação, ao reunir artigos a partir de produções da arte, tais como a pintura e a escultura, do design, da moda e de criações cinematográficas, para nos levar ao passado e ao futuro, ao abordarem questões referentes à curadoria, às tecnologias e à educação.

Entre os vários méritos do livro, o primeiro é o de tornar acessível aos leitores partes do resultado da pesquisa Da dialogia às interfaces: um estudo de relações intertextuais e implicações educacionais em processos de interação por analogia, iniciada desde 2014, junto ao Núcleo de Estudos Semióticos e Transdisciplinares - NEST - vinculado ao Conselho Nacional de Desenvolvimento Científico e Tecnológico - CNPq - e a Universidade de Santa Catarina - UDESC.

O livro reúne artigos que são produtos dessa pesquisa, publicados pelos autores, entre os anos de 2015 a 2020, em periódicos científicos e em anais de congresso. Possibilita maior acesso ao que estava disperso e, por vezes, restrito aos associados de uma entidade que reúne pesquisadores da arte, estudantes e pesquisadores da área de artes e de áreas afins.

Outro mérito é a liberdade dada ao leitor, pela independência entre os capítulos e, ao mesmo tempo, pelo pleno entendimento do conteúdo explorado em cada um deles. Os 14 capítulos podem ser lidos em qualquer ordem que o leitor desejar e conforme o interesse de cada um. Cada capítulo possui uma estrutura 


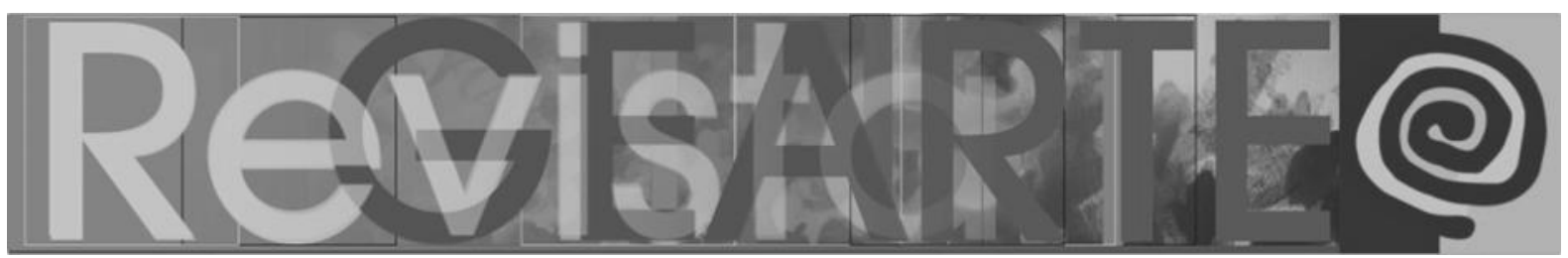

independente e passível de compreensão e, em cada um, os fenômenos de linguagem, tais como os de intertextualidade, dialogia, tradução, paródia, plágio, citação, apropriação e interação vão surgindo, ora para os autores conceituarem e os aprofundarem, ora para com este aporte analisar situações e experiências com a arte, com o design e com a educação.

Em cada um dos capítulos, o tema e o aporte teórico apresentados ao leitor transcorrem em uma escrita clara, coerente e concisa, o que permite a fluidez e a liberdade para que o ledor possa reorganizar, explorar e interagir com o texto, criando os percursos temáticos que preferir. Entre as possibilidades de itinerários admissíveis, embora outras conexões e deslocamentos sejam exequíveis, destaco como exemplo: o de design e das tecnologias, o das reflexões teóricas e o das artes, sendo que este tem suas subdivisões. Os três itinerários citados não possuem uma ordenação hierárquica temática, nem estão em capítulos subsequentes. Entretanto, o tema da educação perpassa todos os capítulos.

O itinerário do design e das tecnologias aponta relações entre design e arte e é desenvolvido especialmente no segundo e sexto capítulos. Versa sobre o conceito e a contextualização da interface, com o argumento de tratar-se de um fenômeno intertextual que assume protagonismo na relação do homem com os computadores, principalmente com a expansão e a acessibilidade da internet. Compara o padrão monetário criado pelo design Aloísio de Magalhães com a produção do artista Cildo Meireles, denominada (Zero) Cruzeiro, a partir dos conceitos de dialogia, bivocalidade e paródia visual.

No itinerário com aprofundamento nas reflexões teóricas, autores como Omar Calabrese e Eric Landowski compõem as bases dos textos presentes nos capítulos primeiro, sétimo e décimo terceiro. Ao conceito de tradução de Calabrese aplicado à visualidade são acrescidas reflexões sobre o uso e propostas para análises comparativas da arte, tendo como eixo os elementos constitutivos e procedimentos relacionais comuns às diferentes linguagens. Aborda a citação e a apropriação na Arte Contemporânea explorando os conceitos a partir de exemplos 


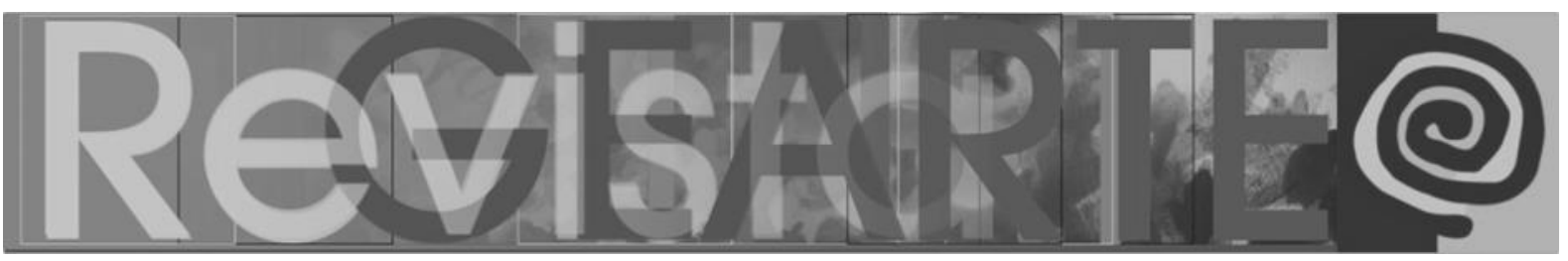

de artistas e produções da arte. Finaliza com um capítulo teórico que tem como base os estudos da interação verbal propostos por Mikhail Bakhtin e os regimes de interação e de sentido preconizados por Eric Landowski.

O mais extenso dos itinerários é o das Artes. Esse pode ser dividido em percursos dos espaços expositivos, tendo como fio condutor as etapas de pesquisas e os deslocamentos da pesquisadora pela França, pela Itália e pelo Brasil. Tal percurso envolve produções artísticas diversas e oriundas de épocas distintas. Envolve desde a gruta de Lascaux IV, aos Museus D'Orsay, Museu Bourdelle, Galleria Nazionalle di Arte Moderna - GNAM - e o Museu da Escola Catarinense - MESC.

Um segundo itinerário das Artes relaciona as Artes Plásticas com outra linguagem e produção artística e /ou cultural, como a Moda, o Cinema e o Design, e em um terceiro estão análises de processos de curadoria, tanto os realizados por profissionais em espaços museológicos como os propostos por estudantes de pósgraduação em artes. Como um itinerário está imbricado no outro, a relação entre a pintura e o cinema e o processo de curadoria de uma mostra retrospectiva realizada em 2018-2019 no Museu D'Orsay podem ser lidos como integrantes de dois diferentes percursos de interesse temático. Assim como as análises comparativas relacionam a gruta de Lascaux IV a movimentos artísticos do século $X X$, retirando-as da necessidade de uma sequência cronológica para uma proposta de estudo que tem como base análises comparativas que consideram os componentes visuais expressivos das obras estudadas.

A relação com a Arte e a Educação compõe um quarto itinerário, em que constam descrições e análises de experiências com estudantes, bem como propostas e sugestões para o ensino da arte a partir de análises comparativas de imagens. Os textos dos capítulos terceiro, quinto e décimo quarto contemplam essas experiências, sem negligenciar a dimensão pedagógica que perpassa todos os capítulos do livro. 


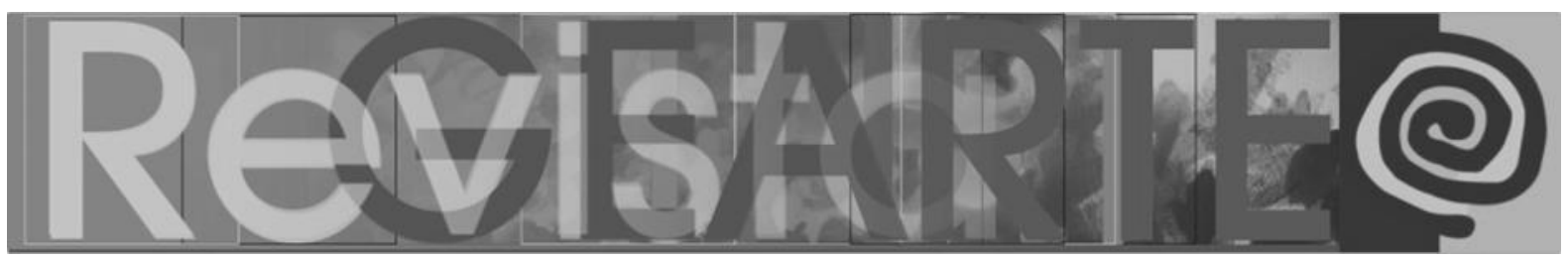

O artigo do terceiro capítulo tem como objetivo apresentar uma proposta para o ensino da arte, trazendo como fio condutor as relações intertextuais em exposições pedagógicas. Essas envolvem estudantes da graduação e da pósgraduação, em ações educativas mediadas e acompanhadas pelo professor, e abrangem desde a concepção da mostra, da curadoria, da montagem, da mediação, até a análise dos resultados. Os três projetos ocorreram entre os anos de 2011 a 2015, em espaços como a Fundação Hassis, a UDESC e o Museu da Escola Catarinense - MESC, todos localizados na cidade de Florianópolis, e foram denominados: Natureza Viva, Quem sou eu e Mil palavras: um museu imaginário.

O quinto capítulo traz um aprofundamento teórico nos conceitos de versão, paráfrase, estilização, apropriação, plágio e citação com referências em autores como Calabrese e Bakhtin. O objetivo do artigo é o de sugerir a intertextualidade em suas diversas formas de manifestação, tais como nos conceitos citados como referência para o ensino da arte, tendo como meta a análise comparativa de imagens tanto da arte como as produzidas culturalmente e presentes em nosso cotidiano. E, para finalizar, o décimo quarto capítulo retoma o conceito de intertextualidade a partir de Julia Kristeva e Mikhail Bakhtin para analisar experiências propostas por mestrandos e doutorandos do Programa de PósGraduação em Artes Visuais - PPGAV, da UDESC. O desafio proposto aos estudantes envolveu a escolha de obras e de destinatários, para a realização de uma experiência teórico-prática, tendo como norteador o conceito de intertextualidade. Lembro ao leitor que os itinerários propostos aqui não são conclusivos, mas somente um exemplo das possibilidades de leitura do livro.

Para concluir, ressalto que as propostas e sugestões apresentadas pelos dois autores e o convite para descobrir outros modos de relação e de interação entre as produções culturais, desprendendo-se dos estudos pautados nas linearidades das cronologias e nas histórias dos movimentos artísticos, exigirão um leitor atento ao plano de expressão e de conteúdo dos textos verbais, visuais e sincréticos e possibilitará que, a depender do interesse e do tema de estudo, possam ser explorados fios e itinerários narrativos sem barreiras de tempo e de 


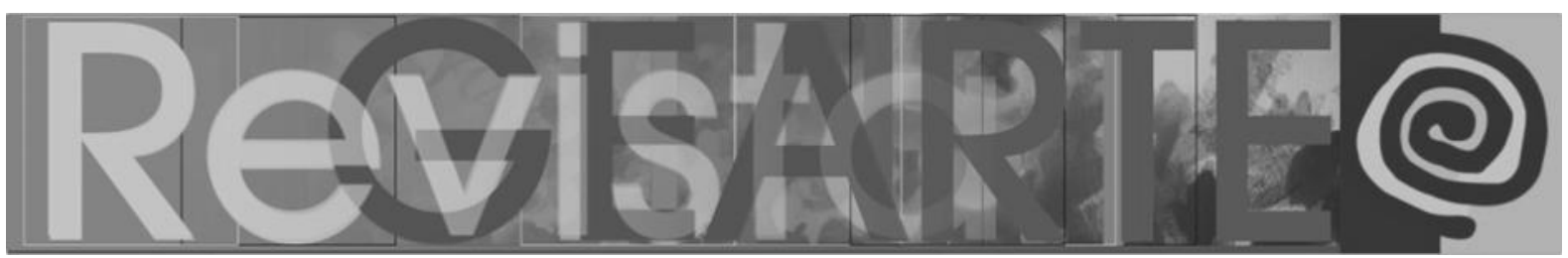

espaço ou do sistema de linguagem. Pintura dialoga com cinema, design, com artes plásticas, moda, com escultura, e a gruta de Lascaux IV pode ser pensada como site specific.

\section{Referência}

OLIVEIRA, Sandra Ramalho; JORDANI, Airton. Intertextualidades visuais. Barueri, SP: Estação das Letras e Cores, 2021.

\section{Moema Martins Rebouças}

Professora Titular da Universidade Federal do Espírito Santo. Integra o grupo de pesquisa do Centro de Pesquisas Sociossemióticas - CPS(PUC/SP), o Instituto de Investigação em Arte, Design e Sociedade no Núcleo de Educação Artística da Faculdade de Belas Artes da Universidade do Porto, Portugal. Líder do GEPEL/CNPq.

ORCID: https://orcid.org/0000-0003-4276-4853

Currículo: http://lattes.cnpq.br/4414451806305375

E-mail:moemareboucas@gmail.com 